\title{
Trepanation and Roman medicine: a comparison of osteoarchaeological remains, material culture and written texts
}

\author{
E Tullo \\ Academic Clinical Fellow, Institute for Ageing and Health, Newcastle University, Newcastle upon Tyne, UK
}

\begin{abstract}
Evidence for prehistoric trepanation is limited to preserved osteoarchaeological material, namely human skulls, and the occasional discovery of surgical instruments. However, the Roman empire gave rise to an abundant and diverse range of source types, including skeletal remains, material culture and detailed medical texts, each of which harbours the potential to contribute to our understanding of trepanation during this historical period. This paper highlights the advantages and inherent biases of each of these source types, and proposes that the simultaneous analysis and integration of different types of historical evidence is essential for the study of trepanation as a surgical procedure.
\end{abstract}

\author{
Correspondence to E Tullo, \\ 7 Cleghorn Street, Heaton, \\ Newcastle upon Tyne NE6 5DJ, UK \\ e-mail ellentullo@doctors.net.uk
}

KEYWORDS Osteoarchaeology, Roman medicine, surgery, trepanation

DECLARATION OF INTERESTS No conflict of interests declared.

\section{INTRODUCTION}

\section{The discovery of trepanation}

Trepanation of the skull is perhaps the earliest recorded surgical procedure in history.' Excitement over this ancient procedure arose in 1865 when the anthropologist Ephraim George Squier returned from a trip to Peru with a prehistoric skull displaying four perpendicular incisions producing a rectangular defect in the right frontal bone. ${ }^{2}$ The skull was presented in 1867 to the French physician Paul Broca, who deduced that evidence of healing around the sites of incision meant that this individual had survived for at least some weeks after the procedure. ${ }^{3}$ In the nineteenth century, when the mortality associated with attempts to open the skull was of the order of $50 \%$, the proposal that ancient people had successfully operated on the skull was received by contemporary critics as incredible. ${ }^{4}$ Following Broca's report on the Peruvian skull, previously overlooked human specimens were re-examined and found to have similar evidence of surgical intervention. The new discovery stimulated the beginning of an ongoing debate on the nature of trepanation throughout the ages, involving a number of interested academic professionals, including scientists, historians and anthropologists. ${ }^{5}$

\section{Definitions and terminology}

Trepanation of the skull may be defined as 'the removal of a piece of calvarium without damage to the underlying blood vessels, meninges and brain'. ${ }^{6}$ There is evidence that trepanation has been performed from prehistory to the present, across a wide geographical range. ${ }^{7}$ An explanation of the motives behind ancient trepanation has continued to be the subject of vigorous debate, while the popularity of the procedure appears to have waxed and waned across the ages. ${ }^{8}$ Twenty-first-century surgeons make use of specially designed tools in order to access the cranial contents, whereas a number of simple methods of trepanation, using a range of tools such as flints and shells, have been used in earlier times (Figure I). ${ }^{6}$

\section{Debates surrounding trepanation}

Prior to the information disclosed by classical medical texts, the motivation for earlier prehistoric trepanation is subject to debate. Opinions tend to two distinct proposals: either that prehistoric trepanation was stimulated by magical or religious beliefs ${ }^{9-11}$ or that it was performed therapeutically to relieve the symptoms of disease according to an understanding of human physiology.,4 There is also debate about rates of survival and complications following trepanation throughout the ages. While there is general consensus that prehistoric and classical trepanation saw impressive levels of post-operative survival, estimations of complications of the procedure are wide-ranging., ${ }^{6,12-14}$ Evidence for prehistoric trepanation is limited to preserved human skulls, and the occasional discovery of surgical instruments. However, a more diverse range of source types, including skeletal remains, material culture and written evidence, is available from the Roman period to contribute to our understanding of trepanation during this historical period.

\section{Roman medicine}

'Roman medicine' can be considered to be significantly influenced by the medicine practised in classical Greece. ${ }^{15}$ As Greek practitioners travelled to Rome to live and work, initial scepticism of Greek doctors and medical theory gradually subsided to allow some integration with the distinct traditional Roman popular medicine, practised largely within the household. ${ }^{16}$ However, suspicion towards Greek doctors persisted to some extent and self-proclaimed medical practitioners were 
not necessarily held in high regard by Roman society. ${ }^{17}$ Despite the availability of a number of medical services, particularly in urban areas, the majority of patients were understood to have relied on simple self-help remedies before considering consulting a practitioner. ${ }^{18}$ Surgery was only considered as a last resort following the failure of more conservative measures such as diet modification or pharmacology. A more highly organised medical service may have existed for slaves, and for the Roman army. ${ }^{19}$ While it has been suggested that the expansion of the Roman empire through military activity constituted a means of rapidly transmitting Roman medical practice over a large part of Europe, ${ }^{20-21}$ recent scholarship examining the cultural diversity among Roman soldiers challenges the idea that any consistent medical service operated within the military. ${ }^{22}$

From a modern perspective, the surgical procedures undertaken by Roman practitioners may be considered to be impressive in terms of the level of surgical skills required and the instrumentation available; thus there is a risk when looking back at this period to try to equate these familiar 'modern' skills with our own current understanding of health and disease. ${ }^{23} \mathrm{It}$ is essential that these apparently modern surgical procedures are analysed in the context of contemporary Roman beliefs. An appreciation of the role of trepanation in Roman medicine requires the examination of source material detailing not only the technicalities of the procedure itself, but also the contemporary beliefs surrounding trepanation that prompted practitioners to suggest, and patients to undertake, such a dramatic intervention.

\section{OSTEOARCHAEOLOGICAL MATERIAL}

In the study of Roman medicine, although a number of written sources exist, the range of texts available is more limited and fragmentary than in recent centuries; thus skeletal remains contribute their own distinct clues. Although the skull provides the most obvious focus for the study of trepanation, extracranial material must not be neglected as it can also yield important information in evaluating the context in which this procedure was performed.

\section{Macroscopic features}

The suggestion that a skull was subject to trepanation is usually prompted by macroscopic evidence of a hole in the calvarium. Such a feature must be differentiated from a number of diverse pathological and pseudo-pathological conditions that may resemble trepanation. ${ }^{24-26}$ By examining the macroscopic features of the human skulls found in a Romano-British cemetery in York, researchers were confident enough to distinguish between several cases of holes: those made by a pick during excavation, a case of pathological erosion and an example of trepanation. $^{27}$ Particular features produced by the method of trepanation, such as linear grooves around

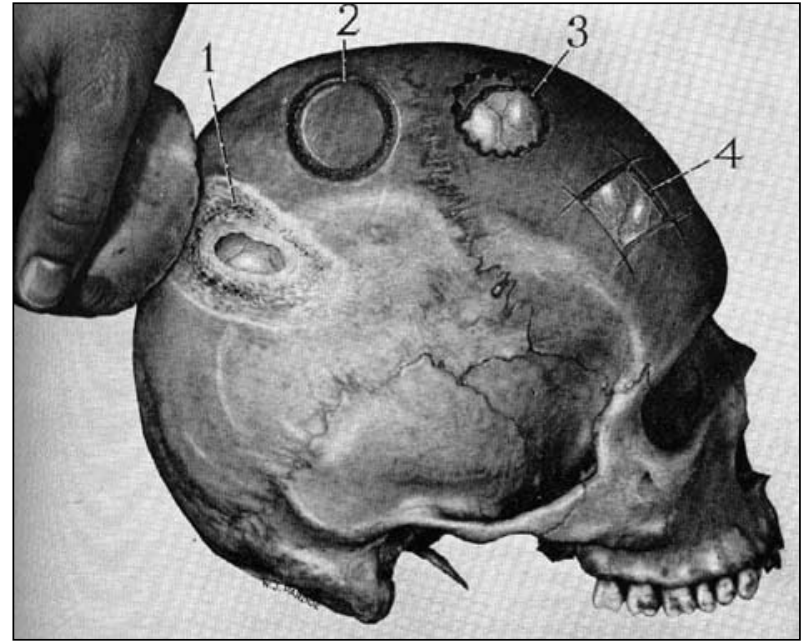

FIGURE I Methods of ancient trepanation: ${ }^{6}$

I Scraping;

2 Chiselling of a circular groove;

3 Joining of adjacent burr holes;

4 Linear grooves.

(With kind permission of Charles C Thomas Publisher.)

the site of the hole, may also be macroscopically evident on the calvarium and contribute to the evidence supporting the identification of trepanation over and above differential aetiology. An example of a Roman child's skull excavated from Fidenae in Italy showed macroscopic track-marking indicative of the surgical procedure. Alongside other evidence, this allowed researchers to come to the conclusion that the patient had undergone trepanation, most likely to have been performed using a chisel. ${ }^{28}$ However, it is important to be aware that the analysis of macroscopic features characteristic of trepanation depends on the state of preservation and excavation of skulls, which may be variable.

Once trepanation is determined as likely, further macroscopic changes at the site can also provide information on whether the patient may have survived the procedure. Any evidence of healing, such as closure of the spongy diploë (the layer of marrow between denser skull bone-plates) and smoothing of the bony edges of the hole, indicates survival of at least days, possibly even weeks, after the surgical procedure. ${ }^{29}$ Such macroscopic evidence was present in trepanned skulls at Fidenae and Cirencester (Figure 2), allowing researchers to conclude that the intervention took place at least some weeks before death. ${ }^{28,30}$ Unfortunately, there is some disagreement as to the macroscopic features conclusively indicative of healing, ${ }^{31-34}$ and thus macroscopic evidence provides an estimate rather than definitive proof of length of survival. Particular difficulty exists in the differentiation between peri- and post-mortem damage. ${ }^{14}$ Trepanation may have been enough of an insult to cause the death of an individual, but it may be impossible to determine whether the procedure caused immediate or eventual death, or whether differential injuries were to blame. 


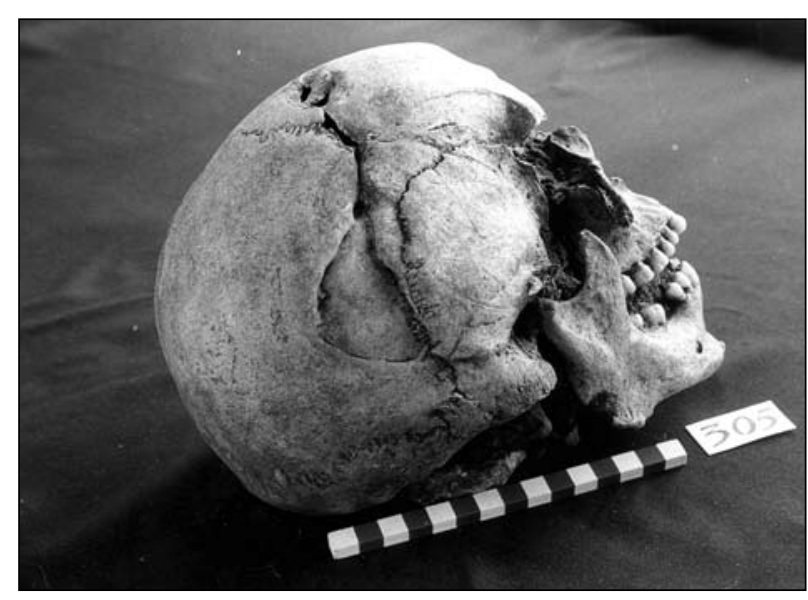

FIGURE 2 Roman skull found at Cirencester, with evidence of traumatic head injury and trepanation. ${ }^{30}$ (With kind permission of the Corinium Museum, Cirencester.)

Additional macroscopic features of trepanned skulls may suggest possible motives for the procedure, although such motives cannot be proven beyond doubt. A trepanned skull found at Cirencester (Figure 2) simultaneously displayed evidence of an extensive head wound and changes consistent with trepanation but with evidence of healing. ${ }^{30}$ The authors concluded that the severity of the head wound would have been likely to have caused significant neurological impairment of the individual; this led to the hypothesis that the relief of this impairment might have constituted a motive for the trepanation. ${ }^{30}$ Co-existent evidence of hydrocephalus in the trepanned child's skull found at Fidenae, just outside Rome, similarly suggested the potential motive of relief of symptoms. ${ }^{28} \mathrm{~A}$ trepanned Roman skull excavated at Whitchurch, Shropshire, showed evidence of extensive dental caries, leading the authors to propose that relief of dental pain might have constituted a motive for surgery. ${ }^{35}$ Although there are numerous examples of skulls found with evidence of both injury and trepanation in other ages, ${ }^{32}$ it is rare to find trepanned skulls from the Roman period with evidence of significant co-existent pathology; thus for the majority of cases, determining the motive for trepanation at this time in history from skeletal material alone is highly speculative.

\section{Other features}

In recent years, the development of more sophisticated microscopic techniques has helped to overcome doubt as to the differential diagnosis of holes in skulls, in deciding, for example, whether surgical instruments have been used. ${ }^{33}$ Researchers have used scanning electron microscopy to compare and contrast the pattern of markings made experimentally by scraping bone with flint, metal and shell; these experimental patterns were compared to a trepanned skull and the differentiating features allowed the authors to conclude in one study that the instrument most likely to have been used was a shell. ${ }^{34}$ Moreover, radiological techniques can shed more light on the features indicative of healing following trepanation. An examination of a skull found in Foggia, Italy, and dated to late imperial Rome, showed that the edges of a hole in the skull were rounded and of uniform thickness, suggesting healing. ${ }^{36}$

\section{Distribution of osteoarcheological material}

Examples of trepanned skulls from the time of the Roman empire are rare, and well-preserved examples more so, possibly due to the Roman custom of cremation. ${ }^{37}$ It is thus difficult to know whether the few individual cases are representative of a widespread practice or an unusual practice concentrated in specific areas. A related bias is pertinent to written sources from the Roman empire; the likely loss of much historical written material introduces the potential distortion in our understanding of what constituted typical contemporary medical and surgical practice. Conversely, the inherent bias of written sources that tend to disproportionately reflect the lives of the literate and the powerful is, to some degree, overcome in the study of osteoarchaeological material.Trepanned skulls provide rare evidence of the impact of medicine on a patient, the individual whose history is most likely to be neglected by traditionally studied written material. Osteoarchaeological evidence can be seen as advantageous in its capacity to capture the 'mute testimony of otherwise unknown patients' ${ }^{38}$

\section{MATERIAL CULTURE}

\section{Surgical instruments}

The Roman custom of burying individuals with objects has resulted in the unearthing of numerous tools that may have been used as surgical instruments (Figure 3) ${ }^{39}$ The discovery of such tools should not lead to immediate assumptions about their use, ${ }^{40}$ but their existence, as appraised in the relevant archaeological context, may add to the macroscopic and microscopic evidence from osteoarcheological material to suggest surgical intervention. Even detailed written descriptions of surgical instruments cannot confirm their exact size, shape and material composition; preserved examples contribute supplementary physical evidence of some of these missing values. Examples of tools that may have been used for trepanation include the raspatory (scraper), chisel, gouge, hammer, meningophylax (metal piece to protect the dura mater), drill and crown saw (or modiolus - a shallow cylinder of metal with a sharp edge rotated against the skull surface) (Figure 3). ${ }^{41}$ The choice of instrument type was likely to have been determined by the particular clinical features of each case, for example the size and position of a skull fracture, and the preference of the medical practitioner. ${ }^{37,42}$

\section{Analysis of material culture}

The most immediate problem in the analysis of material culture such as surgical instruments is diversity in the degree of preservation, which is largely dependent on 
material composition. Roman surgical instruments were made of a number of materials, including wood, metal and woven material. Metals used in the crafting of surgical instruments included gold, silver, copper, tin, lead, iron, zinc and a number of alloys including bronze. ${ }^{43}$ Stable and robust metals such as bronze are most likely to survive, while iron is the metal most likely to perish in the passage of time. ${ }^{37}$ Adjuncts to surgical intervention such as dressings and bandages are particularly vulnerable to decomposition. This diversity in preservation introduces an additional inherent bias in deciding which examples of material culture were made frequent use of. Moreover, the assumption that instruments are Roman in date is often made only because they are found in conjunction with material that can be dated more reliably.

\section{Linking instrumentation to procedure}

The existence of sophisticated surgical instruments in isolation cannot be assumed to indicate a high level of surgical skill. ${ }^{16}$ There exists a temptation to recognise these instruments in relation to modern surgical procedure; instead, these tools may have been used differently by Roman practitioners. Modern ergonomic considerations can be applied to ancient instruments to suggest the possible technique used, ${ }^{44}$ but in order to qualify this technique, instrumentation should be examined alongside skeletal remains and written texts. An example of a skull found at York exhibits features of trepanation consistent with the proposal that a crown saw of the type found separately at Bingen, Germany, was used in practice. The external limits of the skull perforation are described as perfectly symmetrical and with no evidence of cuts or grooves beyond this margin. ${ }^{33}$

The study of the types of instruments and techniques that have been used to trepan skulls over time can assist our estimation of the date of the introduction of particular instruments. The majority of Iron Age skulls found, before the presence of the Romans, show evidence of trepanation by scraping, whereas none show evidence of the use of a circular crown saw. ${ }^{37,45}$ The example given of a Roman skull with evidence of use of the crown saw, alongside the extant Roman material culture and the description of its use in Roman texts, invites the tentative hypothesis that this instrument was of Graeco-Roman origin. ${ }^{37}$

\section{MEDICAL TEXTS}

\section{Indications for trepanation}

Although occasional examples of co-existent pathology visible alongside evidence of trepanation in osteoarchaeological samples might suggest a motive for trepanation, knowledge of all the accepted indications for trepanation in Roman medicine cannot be derived from skeletal remains or material culture. Perhaps the greatest strength of written material is its ability to provide clues as to the reasoning that lay behind the perceived benefits of

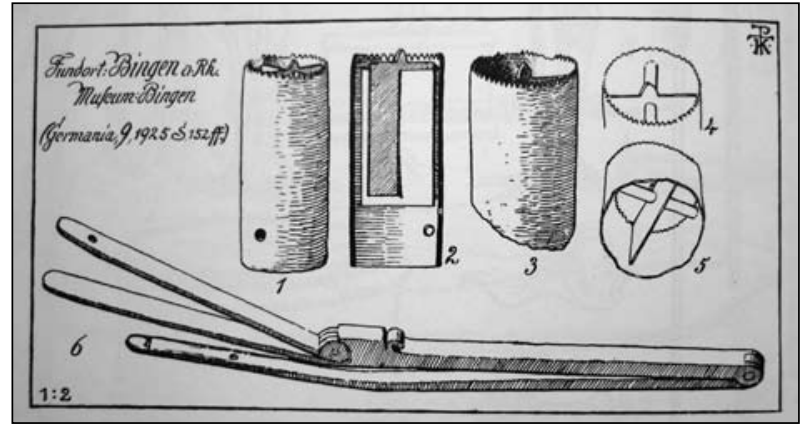

FIGURE 3 Illustration of instruments found at Bingen, Germany: I-5 crown trephine, 6 iron chisel. (Taken from Künzl. ${ }^{39}$ Every effort has been made to trace the copyright holder.)

trepanation as a surgical intervention. The earliest written records of trepanation in Greek medicine come from the Hippocratic Corpus.? Places in man, agreed to be one of the earliest texts of the Corpus, describes the particular types of skull fractures that require surgical intervention:

Cases of fracture of the skull: if the bone is broken and split, there is no danger; and if this patient should be treated by moistening drugs. But if it is broken and there is a fissure-fracture, it is dangerous. You should trephine this case, to prevent pus from flowing through the fracture of the bone and infecting the membrane; for, since in this narrow place it can get in but not out, it causes distress and madness. ${ }^{46}$

Another text of the Hippocratic Corpus, On head wounds, delineates in more detail the different types of skull fractures and which of these were most imperative to trepan. ${ }^{47}$ On head wounds does not make explicit the underlying reasoning as to why trepanation was considered advantageous, but the quotation from Places in man suggests that creating a passage for the exit of pus might prevent complications of a skull injury. Later, Celsus, a Roman encyclopaedist writing in the early first century $A D$, may have been describing trepanation when he endorsed 'assistance' where harmful material had collected around the brain and bone fragments risked damaging the brain surface:

Hence it follows that humour collects on to the cerebral membrane but has no means of exit, and so irritates it, exciting severe inflammation. But when there is a depressed fracture, the bone presses on the cerebral membrane and sometimes also sharp points like needles from the fractured bone cause irritation. Cases like this require assistance with as little loss of bone as possible. ${ }^{48}$

Galen, the important and influential Roman medical practitioner, philosopher and author, agreed that some skull fractures required therapeutic trepanation in order to relieve pressure. ${ }^{49}$ Galen's explanation of the benefit of this intervention was based on his understanding of the role of the ventricles of the brain and pneumatic 
physiology; he described trepanation as easing the pressure of pneuma in the ventricles leading to a diminution of pain.

While head injury was frequently cited as an indication for trepanation by a number of Graeco-Roman authors, other indications included epilepsy, headache and paralysis (which may, of course, have been subsequent complications of a primary head injury). ${ }^{7.50}$ Clinical indications other than head injury seem to have been controversial; authors such as Aretaeus of Cappadocia, a first-century Greek physician, advocated trepanation for epilepsy once conservative measures had failed, ${ }^{51}$ while Caelius Aurelianus, a fifth-century Roman physician, criticised other practitioners for causing harm in such cases. $^{52}$ It is impossible to know whether lost texts spoke of other indications or whether trepanation, apparently commonly undertaken by urban practitioners, was a reality for the majority of the population who lived in rural areas. ${ }^{53}$

\section{Surgical method and skill}

It has been suggested that the descriptions of surgical procedures such as trepanation, provided by medical texts, are not necessarily representative of craft practice. ${ }^{54}$ While undoubtedly a practitioner might be compelled to promote himself in text as more able than in reality, detailed descriptions of the trepanning procedure can aid our understanding of the technique employed in the use of the material culture discussed above. Celsus provides detailed descriptions of a number of methods of trepanation and the instruments used:

When the disease is so limited that the modiolus can include it, this is more serviceable; and if the bone is carious, the central pin is inserted into the hole; if there is black bone, a small pit is made with the angle of the chisel for the reception of the pin, so that, the pin being fixed, the modiolus when rotated cannot slip; it is then rotated by means of a strap. The pressure must be such that it both bores and rotates; for if pressed lightly it makes little advance, if heavily it does not rotate. ${ }^{48}$

While such a text alone cannot prove that this technique was used in practice, the co-existent examples of surviving instruments and trepanned skulls with evidence of the use of these instruments cumulatively add to a body of evidence that indeed this was a procedure undertaken by Roman practitioners.

Written records also suggest that practitioners were aware of the technical difficulties of trepanation, and duly weighed up the expected benefits of trepanation with the risk of causing harm. Aretaeus brands trepanation a 'bold' remedy, ${ }^{1}$ ' while Galen describes the potential risk of damage to the brain, and emphasises that this skill would need to be practised numerous times for the operator to become proficient. ${ }^{42}$ The acknowledged complications of trepanation meant that a practitioner would have to have made a considered clinical decision as to whether intervention would be more likely to engender benefit than cause harm. While some examples of Roman skulls show evidence of healing, indicating survival of at least weeks to months, others do not; it is clear in this respect that the pathological conditions that necessitated trepanning and the inherent risks of the procedure as described by written texts, consolidates the bio-archaeological evidence available.

\section{Patient experience}

Many surviving written resources provide generic advice on surgical technique, but detailed information about individual patient experience of intervention is rarer. However, Aretaeus provides his readers not only with a description of the physical suffering of patients with epilepsy, but also some insight into the acute social embarrassment experienced by these patients:

Of remedies, whatever is great and most powerful is needed for epilepsy, so as to find an escape not only from a painful affection, and one dangerous at each attack, but from the disgust and opprobrium of this calamity. For it appears to me, that if the patients who endure such sufferings were to look at one another in the paroxysms, they would no longer submit to live. ${ }^{5}$

Statements thus begin to aid our understanding of why a Roman patient might agree to undergo a procedure as risky as trepanation, in an age where analgesia for surgical intervention was rarely effective.

Osteoarchaeological samples and material culture are able to suggest that trepanation involved the use of a specially designed instrument in order to perforate the skull, but the lack of survival of surgical adjuncts such as dressings and poultices fails to provide physical evidence of treatment that patients might have received before and after trepanation. Written texts, however, can offer descriptions of the longer-term treatment that patients may have received as part of their experience of injury and treatment. Hippocrates, in On head wounds, writes of the pre-operative procedures required to determine whether a head wound was amenable to trepanation. Once the scalp had been incised, the practitioner is instructed to:

[...] pack the entire wound with lint dressing in order to keep the wound as wide as possible until the next day with the least pain. After packing [the wound] you must use as a poultice, for as long a time as the packing, a dough made of fine barley meal; knead it with vinegar and boil it and make it as glutinous as possible. ${ }^{47}$ 
Evidently, medical texts can add to our knowledge of adjuvant features of the trepanation procedure, as experienced by a patient, that are not apparent from osteoarchaeological samples and material culture alone.

\section{Problems with medical texts}

While written texts have been described as 'the most important single source' in understanding Roman medicine, ${ }^{23}$ they cannot be assumed to be free from distinct problems of interpretation. Medical discourses usually record the voice and opinions of a single practitioner; the comparison of texts shows that health professionals differed in their understanding of disease and in the methods that they employed to treat it. ${ }^{55}$ This variation inevitably leads to difficulties in determining which teachings and practices concerning trepanation were most widely accepted. Moreover, in the GraecoRoman world, a practitioner's income and reputation was affected by the competing interests of others, and the self-promotion and rhetoric associated with enhancing a personal reputation cannot fail to be reflected in written texts. ${ }^{15}$

\section{REFERENCES}

I Margetts EL. Trepanation of the skull by the medicine-men of primitive cultures, with particular reference to present day native East African practice. In: Brothwell DR, Sandison AT, editors. Diseases in antiquity. Springfield: CC Thomas; 1967. p. 673-70I.

2 Fernando HR, Finger S. Ephraim George Squier's Peruvian skull and the discovery of cranial trepanation. In: Arnott R, Finger S, Smith C, editors. Trepanation: history, discovery, theory. Lisse: Swets and Zeitlinger; 2003. p. 3-18.

3 Finger S, ClowerWT. On the birth of trepanation. The thoughts of Paul Broca and Victor Horsley. In: Arnott R, Finger S, Smith C, editors. Trepanation: history, discovery, theory. Lisse: Swets and Zeitlinger; 2003. p. 19-42.

4 Prioreschi P. A history of medicine. Vol I. Primitive and ancient medicine. 2nd ed. Omaha: Horatius Press; 1996. p. 21-33.

5 Ackerknecht EH. Contradictions in primitive surgery. Bull Hist Med 1946; 20:184-7.

6 Lisowski FP.Prehistoric and early historic trepanation. In:Brothwell DR, Sandison AT, editors. Diseases in antiquity. Springfield: CC Thomas; 1967. p. 65I-2.

7 Gross CG. Trepanation from the paleolithic to the internet. In: Arnott R, Finger S, Smith C, editors. Trepanation: history, discovery, theory. Lisse: Swets and Zeitlinger; 2003. p. 307-22.

8 Martin G. Why trepan? Contributions from medical history and the South Pacific. In: Arnott R, Finger S, Smith C, editors. Trepanation: history, discovery, theory. Lisse: Swets and Zeitlinger; 2003. p. 323-45.

9 Sigerist HE. A history of medicine.Vol I. Primitive and archaic medicine. New York: Oxford University Press; 195I. p. I I0-3.

10 Oakley KP, Brooke WMA, Akester AR et al. Contributions on trepanning or trephination in ancient and modern times. Man 1959; 59:93-6. doi: 10.2307/2797/26

I I Castiglioni A. A history of medicine. New York:Alfred A Knopf; 1947. p. 27.

I2 Roberts CA, Manchester K. The archaeology of disease. Gloucester: Sutton Publishing; 1997. p. 91.

I3 Majno G. The healing hand. Man and wound in the ancient world Cambridge (Mass.): Harvard University Press; 1975. p. 28.

14 Ortner DJ. Identification of pathological conditions in human skeletal remains. London: Routledge; 2000. p. 70-3, 173.

\section{CONCLUSION}

Sources pertaining to Graeco-Roman trepanation include osteoarchaeological material, preserved instrumentation and medical texts. Clearly, all sources have the potential to add specific information and are all accompanied by their own distinct barriers to valid interpretation. The strengths and weaknesses of each source type necessitate that they are analysed concurrently; thus the deficiencies apparent in the analysis of one source type are to some degree supplemented by the strengths of another. The successful study of skull trepanation and its place in Graeco-Roman medicine requires the contribution and co-operation of a number of interested academic disciplines; their specialist skills in the interpretation of specific source material must be shared to bring together evidence that is as robust and objective as possible.

I5 Nutton V. Healers in the medical market place. Towards a social history of Graeco-Roman medicine. In:Wear A, editor. Medicine in society: historical essays. Cambridge: Cambridge Univesity Press; 1992. p. I5-58. doi: I0.I0I7/CBO97805 I I599682.002

16 Scarborough J. Roman medicine. Ithaca: Cornell University Press; 1976. p. 37-45, 86.

17 King H. Greek and Roman medicine. London: Bristol Classical Press; 200I. p.32-7.

I8 Nutton V. Roman medicine. In: Conrad LI, Neve M, Nutton V et al., editors. TheWestern medical tradition:800BC to AD /800. Cambridge: Cambridge University Press; 1995. p. 39-70.

19 Scarborough J. Roman medicine and the legions.A reconsideration. Med Hist 1968; |2:254-6।.

20 Nutton V. Medicine and the Roman army. A further reconsideration. Med Hist 1969; 13:260-70.

21 Davies RW.The Roman military medical service. Saalburg Jahrbuch 1970; 27:84-104.

22 Baker P. Medical care for the Roman army on the Rhine, Danube and British frontiers in the first, second and early third centuries $A D$. $\mathrm{PhD}$ thesis. Newcastle: Newcastle University; 2000.

23 Jackson R. Roman doctors and their instruments. Recent research into ancient practice. J Rom Archaeol 1990; 3:5-27.

24 Ackerknecht EH. Primitive surgery. Am Anthropol 1947; 49:25-45. doi:I0.1525/aa.1947.49.1.02a00030

25 Kaufman MH, Whitaker D, McTavish J. Differential diagnosis of holes in the calvarium. Application of modern clinical data to paleopathology. J Archaeol Sci 1997; 24:193-218. doi:10.1006/ jasc.1995.0104

26 Wells CW. Pseudopathology. In: Brothwell DR, Sandison AT, editors. Diseases in antiquity. Springfield: CC Thomas; 1967. p. 5-19.

27 Wenham LP. Romano-British cemetery at Trentholme Drive, York. London: HMSO; 1968. p. II5-6.

28 Mariani-Constantini R, Catalano P, di Gennaro F et al. New light on cranial surgery in ancient Rome. Lancet 2000; 355:305-7. doi:I0.I0I6/S0I40-6736(99)05064-3

29 Brothwell DR. Digging up bones. The excavation, treatment and study of human skeletal remains. London; British Museum; I98I. p. I22. 
30 McWhirr A, Viner L, Wells C, editors. Romano-British cemeteries at Cirencester. Cirencester: Cirencester Excavation Committee Corinium Museum; 1982. Microfiche 4/5.

31 Stewart TD. Significance of osteitis in ancient Peruvian trephining. Bull Hist Med 1956; 30:293-320.

32 Andrushko VA, Verano JW. Prehistoric trepanation in the Cuzco region of Peru. Am J Phys Anthropol 2008; I37:4-I3. doi:I0.I002/ ajpa.20836

33 Brothwell DR. Osteological evidence of the use of a surgical modiolus in a Romano-British population. An aspect of primitive technology. J Archaeol Sci 1974; I:209-II. doi:I0.1016/03054403(74)90044-2

34 Stevens GC, Wakely J. Diagnostic criteria for identification of seashell as a trephination implement. Int J Osteoarchaeol 1993; 3:167-76. doi:10.1002/oa.1390030303

35 Jones GDB, Webster PV. Mediolanum. Excavations at Whitchurch 1965-6. Archaeol J 1968; 125:193-254.

36 Scattarella V, Sublimi Saponetti S, Cuscianna $N$ et al. A case of skull trephination from late imperial Rome.J Paleopathol 1996; 8:85-8.

37 Jackson R. Holding on to health? Bone surgery and instrumentation in the Roman Empire. In: King H. Health in antiquity. London: Routledge; 2005. p. 97-120. doi: I0.4324/9780203323847_chapter_5

38 Jackson R. Doctors and disease in the Roman Empire. London: British Museum Press; 1988. p. II8.

39 Künzl E. Medizinische Instrumente aus Sepulkralfunden der römischen Kaiserzeit. Cologne: Rheinland-Verlag; 1983. p. 5-6.

40 Baker P. Diagnosing some ills: the history and archaeology of Roman medicine. In: Baker P, Carr G, editors. Practitioners, practices and patients: new approaches to medical archaeology and anthropology. Oxford: Oxbow Press; 2002. p. 16-29.

4I Milne JS. Surgical instruments in Greek and Roman times. Oxford: Clarendon Press; 1907.

42 Rocca J. Galen on the brain. Anatomical knowledge and physiological speculation in the second century $A D$. Leiden: Brill Academic Publishers; 2003. p. 75-6, 183.
43 Longfield-Jones GM. Surgical instruments. In: Healy JF. Mining and metallurgy in the Greek and Roman world. London: Thames and Hudson; 1978. p. 246-50.

44 Kirkup J.The evolution of cranial saws and related instruments. In: Arnott R, Finger S, Smith C, editors. Trepanation: history, discovery, theory. Lisse: Swets and Zeitlinger; 2003. p. 290-304.

45 Parker S, Roberts CA, Manchester K. A review of British trepanation. Ossa 1986; I2:|4|-57.

46 Hippocrates. Places in man. Oxford: Clarendon Press; |998. p. 71.

47 Hippocrates. On head wounds. Berlin: Akademie Verlag; 1999. p. 8I.

48 Celsus. On medicine. Vol. III. Cambridge (Mass): Harvard University Press; 1938. p. 497, 513.

49 Rocca J. Galen and the uses of trepanation. In: Arnott R, Finger S, Smith C, editors. Trepanation: history, discovery, theory. Lisse: Swets and Zeitlinger; 2003. p. 253-7I.

50 Temkin O. The falling sickness: a history of epilepsy from the Greeks to the beginnings of modern neurology. Baltimore: Johns Hopkins University Press; 197I. p. 3.

51 Adams F, editor. The extant works of Aretaeus the Cappadocian. Boston: Milford House; 1856. p. 46I, 468-9.

52 Aurelianus C. On acute diseases and on chronic diseases. Chicago: University of Chicago Press; 1950. p. 517, 523, 603-4.

53 Pleket HW. The social status of physicians in the Graeco-Roman world. In: Van der Eijk PJ, Horstmanshoff HF, Schrijvers PH, editors. Ancient medicine in its socio-cultural context. Leiden: Rodopi $\mathrm{Bv}$ Editions; 2005. p. 27-34.

54 Lawrence G. Surgery (traditional). In: Bynum W, Porter R, editors. Companion encyclopedia of the history of medicine. Vol 2. London: Routledge; I993. p. 96I-83.

55 Nutton V. Ancient medicine. London: Routledge; 2004. p. 270-I.

\section{CONFERENCING AND EVENTS}

The Royal College of Physicians of Edinburgh has a unique blend of rooms providing perfect surroundings for your conference, meeting or event. The Victorian Great Hall, galleried New Library and the Georgian Cullen Suite are wonderful settings for dinners and receptions. The modern Conference Centre seats up to 300 people in raked seating and is complemented by breakout rooms seating from 10 to 150 people, a keypad voting system and video conferencing. The College provides a stunning setting for weddings and receptions and is licensed for both civil and religious ceremonies. Discounts are available for Fellows and Members, medical conferences and charities.

For more information or for a quotation, please contact the Events Team on +44 (0) I3। 225 7324; email events@rcpe.ac.uk or visit http://www.rcpe.ac.uk/conferencing/index.php

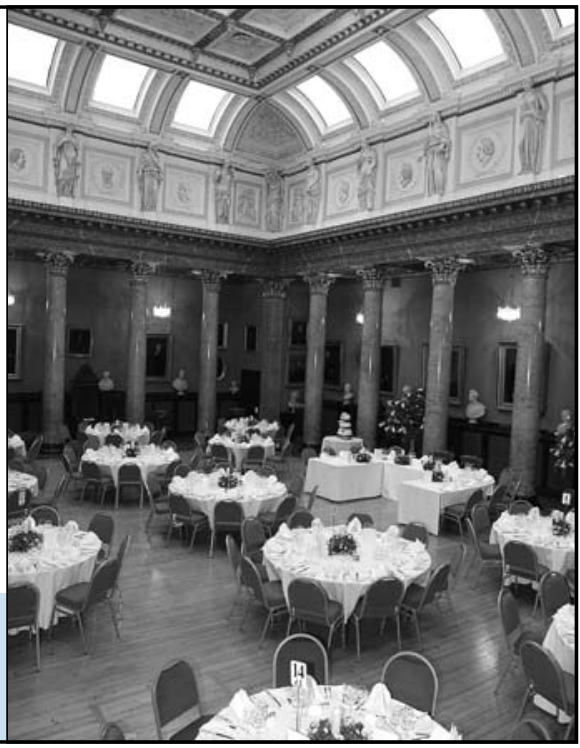

